\title{
The analgesic effect of nitroglycerin added to lidocaine on quality of intravenous regional anesthesia in patients undergoing elective forearm and hand surgery ${ }^{1}$
}

\author{
Hosein Kimiaei Asadi', Dariush MehriII
}

IAssistant Professor, Department of Anesthesiology, Hamadan University of Medical Sciences, Hamadan, Iran. Conception and design of the study, acquisition of data, final approval.

IIAssistant Professor, Department of Anesthesiology, Hamadan University of Medical Sciences, Hamadan, Iran. Conception and design of the study, acquisition of data, manuscript writing.

\begin{abstract}
PURPOSE: To evaluate the effect of nitroglycerine (NTG) on sensory and motor block onset and recovery time as well as the quality of tourniquet pain relief, when added to lidocaine (LID) for intravenous regional anesthesia in elective forearm and hand surgery.

METHODS: A randomized double-blinded clinical trial was performed on 40 patients that were randomly allocated into two groups received lidocaine $3 \mathrm{mg} / \mathrm{kg}$ with NTG $200 \mu \mathrm{g}$ or received only lidocaine $3 \mathrm{mg} / \mathrm{kg}$ as the control.

RESULTS: There was no difference between the two study groups in hemodynamic parameters before tourniquet inflation, at any time after inflation and after its deflation. There was no difference in the mean of pain score over time between the two groups. The onset time of sensory and motor blockades was shorter in the group received both LID and NTG. The mean recovery time of sensory blockade was longer in the former group. The frequency of opioid injections was significantly lower in those who administered LID and NTG.

CONCLUSION: The adjuvant drug of NTG when added to LID is effective in improving the overall quality of anesthesia, shortening onset time of both sensory and motor blockades, and stabling homodynamic parameters in hand and forearm surgery.
\end{abstract}

Key words: Analgesia. Lidocaine. Nitroglycerin. Pain. Surgery. 


\section{Introduction}

Intravenous regional anesthesia (IVRA) was described first in 1908 as anesthetic protocol for operation of the hand and forearm and has been commonly used for providing anesthesia and analgesia during the operation, because of its simple application, reliability, as well as cost-effectiveness ${ }^{1}$. In this context, using additives can help to prolong the duration of postoperative analgesia and reduce postoperative pain ${ }^{2,3}$. Nowadays, various additives to analgesic agents have been identified to reduce tourniquet pain, improve block quality, as well as prolong post-deflation analgesia, including opioids, non-steroidal antiinflammatory drugs, corticostroids, and muscle relaxants ${ }^{4}$. But, because of some considerable side effects such as drug toxicity, slow onset and even inability to inducing effective postoperative pain relief, their administration has been significantly limited ${ }^{5}$. Some recent studies evidenced the beneficial role of the addition of nitroglycerine (NTG) to other analgesics such as lidocaine (LID) for improving sensory and motor blockade, tourniquet pain, and also postoperative analgesia ${ }^{6,7}$. But the results have been controversy because of different administered drug dosages ${ }^{8}$.

We therefore designed this study to evaluate the effect of NTG on sensory and motor block onset and recovery time, the quality of tourniquet pain relief, and postoperative hemodynamic stability when added to LID for IVRA in patients who undergoing elective forearm and hand surgery.

\section{Methods}

The trial was registered with and approved by the Research Ethics Committee of Hamadan University of Medical Sciences and Iranian Registry of Clinical Trials.

In a randomized double-blinded clinical trial, 40 patients scheduled for elective forearm and hand surgery were included in the study. All patients aged older than 15 years, weight ranged 50 to $90 \mathrm{~kg}$, and had ASA physical status I and II. None of the patients had contraindications for supraclavicular block or sensitivity to the administered drugs. Those with unsuccessful blockade, history of chronic liver or kidney diseases, pregnancy, any premedication such as NTG, narcotics, benzodiazepines, or clonidine or those who refused to participate in the study were all excluded. Those with the history of cardiac arrhythmias, neuromuscular disorders, drug allergy, Sickle-cell anemia, or Raynaud's disease, as well as the patients with the history of Sildenafil use or other similar medications influencing blood flow and muscles relaxation were also not included.
On arrival to the operating room, standard monitoring was established (pulse oximetry, electrocardiography, and noninvasive arterial blood pressure monitoring), and oxygen was delivered via a single facemask. After insertion of a 20 -gauge IV catheter in a peripheral vein in the contralateral arm, $30 \mu \mathrm{g} / \mathrm{kg}$ IV midazolam and $1 \mu \mathrm{g} / \mathrm{kg}$ IV fentanyl administered as premedication. Tourniquet consisted of two cuffs placed on the proximal aspect of the arm and inflated to $300 \mathrm{mmHg}$ and then analgesic drug was injected slowly within 60 seconds through a catheter. The studied patients were randomly allocated into two groups received lidocaine $3 \mathrm{mg} /$ $\mathrm{kg}$ with NTG $200 \mu \mathrm{g}$ as the case group, or received only lidocaine $3 \mathrm{mg} / \mathrm{kg}$ as the control group. All local anesthetic solutions and adjuvant drugs were prepared by an anesthesiologist who was not involved in the performance of block, patient care, or data collection. After injection, the onset time of sensory blockade was checked via a 22-gauge IV catheter in the location of sensory dermatomes of Ulnar nerve (fingers 4 and 5), Radial nerve (dorsal surface of fingers 1,2, and 3), and Median nerve (medial surface of fingers 1, 2, and 3).

The motor blockade was also assessed by inability to grip the fingers or wrist flexion. The duration of sensory block was considered as the time interval between the complete sensory block and the first postoperative pain, and the duration of motor block was defined as the time interval between the complete paralysis and complete recovery of motor function. Vital parameters of patients including heart rate (HR), systolic blood pressure (SBP), diastolic blood pressure (DBP), and arterial oxygen saturation $\left(\mathrm{SaO}_{2}\right)$ were recorded immediately before tourniquet inflation, 5, 10, 15, 20, 30 , and 40 minutes after inflation and also immediately after tourniquet deflation. In addition, the patients were familiarized with a 10-point verbal analog scale (VAS) (0 indicated no pain and 10 indicated the worse imaginable pain) at these time points for assessing level of pain. In case of pain within operation, $1 \mu \mathrm{g} /$ $\mathrm{kg}$ IV fentanyl was administered. From tourniquet inflation to 6 hours after surgery and based on the patients' request, methadone $5 \mathrm{mg}$ IM was administered and its dosage and frequency was recorded. Recovery time of sensory block was defined as the time interval between tourniquet deflation and anesthesia disappearing and recovery time of motor block was defined as the time interval between deflation of tourniquet and acquire the ability to fingers or wrist flexion. After the surgery, the surgeons were asked about the pain quality based on the following scoring: (4) very good (without any complain from the patient); (3) good (with a mild reported pain but not needed to analgesic; (2) moderate (with a mild reported pain but needed to analgesic administration; and (1) severe (lead to general anesthesia). The patients were also asked 
about the pain quality based on the following scoring: (0) none (without any pain description); (1) mild pain (report the pain to physician but without any facial symptoms); (2) moderate (pain description with appearing facial or body manifestations; and (3) severe (patient's complain with evidenced changes as crying or frowning.

Results were reported as mean \pm standard deviation (SD) for the quantitative variables and percentages for the categorical variables. The groups were compared using the t test or MannWhitney $U$ test for the continuous variables and the chi-square test (or Fisher's exact test if required) for the categorical variables. Trend of the changes in homodynamic parameters were assessed using the repeated measure for ANOVA test. P values of 0.05 or less were considered statistically significant. All the statistical analyses were performed using SPSS version 16.0 (SPSS Inc., Chicago, IL, USA).

\section{Results}

The overall mean age of study population was $31.21 \pm$ 14.57 years (ranged 16 to 81 years) and $75 \%$ of them were male. The study participants who received LID and NTG and those who administered only LID were similar with respect to the average age $(32.37 \pm 18.18$ years versus $30.10 \pm 10.43$ years, $p=0.633)$, male to female ratio (both groups, 15 to 5$)$, and mean weight (68.72 \pm $11.28 \mathrm{~kg}$ versus $63.66 \pm 7.20 \mathrm{~kg}, \mathrm{p}=0.114)$. Regarding measures of hemodynamic parameters (Table 1), there was no significant difference between the two study groups in HR, SBP, DBP, and $\mathrm{SpO} 2$ before tourniquet inflation, at any time after inflation as well as after its deflation, except for measured heart rate 15 minutes before tourniquet inflation that was slightly higher in the group received both drugs (Mann-Whitney U test).
Assessing trends of the changes in hemodynamic indices across the two groups showed no significant differences between them (the repeated measure ANOVA test) (Figures 1 and 2).

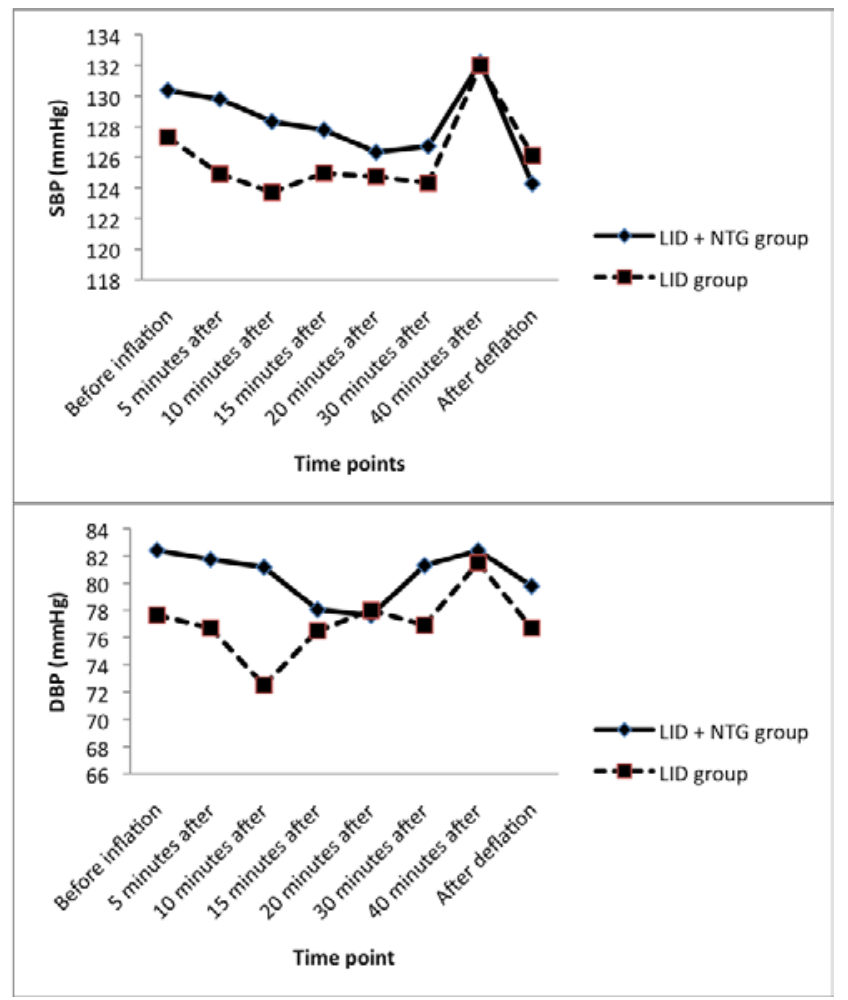

FIGURE 1 - Trend of the changes in systolic and diastolic blood pressures.

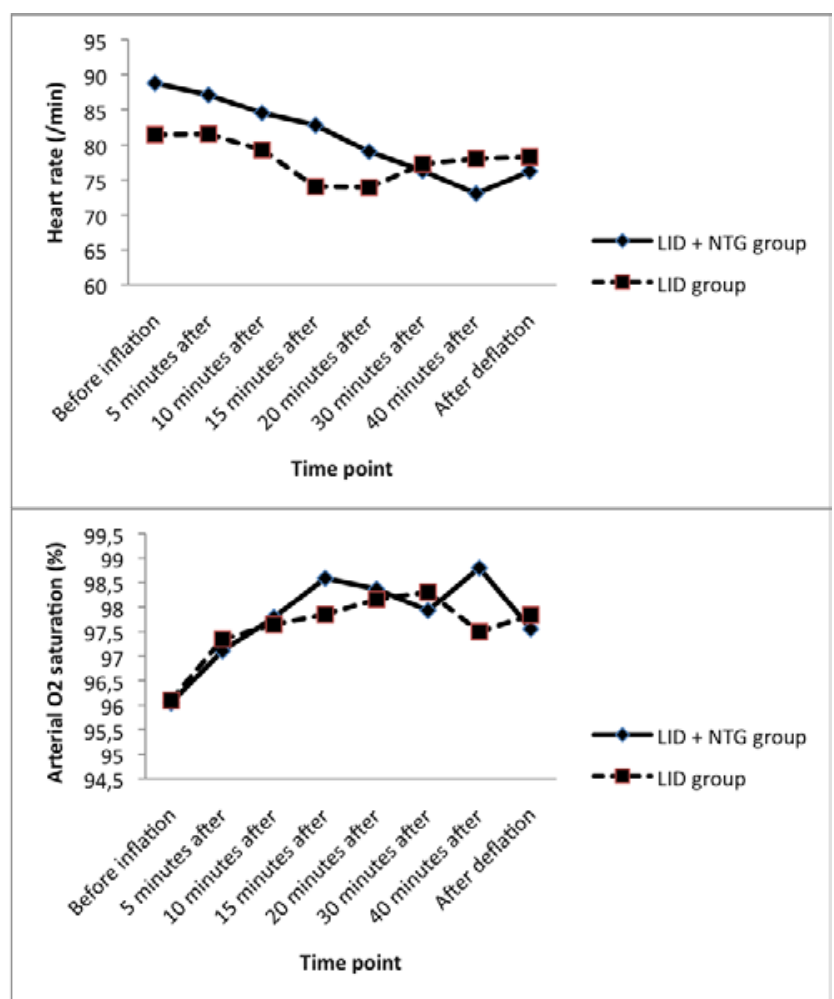

FIGURE 2 - Trend of the changes in heart rate and arterial $\mathrm{O}_{2}$ saturation.

There was also no significant difference in the mean of VAS score for pain measured over time between the two groups $(\mathrm{t}$ test) (Table 2). 
TABLE 1 - Hemodynamic parameters before inflation tourniquet, during anesthesia, and after deflation.

\begin{tabular}{cccc}
\hline & $\begin{array}{c}\text { LID + NTG group } \\
(\mathrm{n}=20)\end{array}$ & $\begin{array}{c}\text { LID group } \\
(\mathrm{n}=20)\end{array}$ & P value \\
\hline Systolic blood pressure & & & \\
Before tourniquet inflation & $130.37 / 12.69$ & $127.30 / 9.67$ & 0.40 \\
5 minutes after & $129.79 / 13.98$ & $124.90 / 13.01$ & 0.26 \\
10 minutes after & $128.32 / 14.57$ & $123.70 / 12.51$ & 0.29 \\
15 minutes after & $127.79 / 15.74$ & $124.96 / 10.95$ & 0.47 \\
20 minutes after & $126.32 / 14.07$ & $124.74 / 13.02$ & 0.72 \\
30 minutes after & $126.71 / 16.81$ & $124.31 / 15.12$ & 0.70 \\
40 minutes after & $132.20 / 24.18$ & $132.00 / 10.23$ & 0.98 \\
After tourniquet deflation & $124.26 / 13.73$ & $126.10 / 11.92$ & 0.65
\end{tabular}

Diastolic blood pressure

Before tourniquet inflation

$82.42 / 10.39$

5 minutes after

10 minutes after

15 minutes after

20 minutes after

30 minutes after

40 minutes after

After tourniquet deflation
$81.74 / 15.50$

$81.16 / 15.29$

$78.05 / 13.05$

$77.63 / 10.27$

$81.29 / 14.43$

$82.40 / 20.46$

$79.79 / 10.23$
$77.65 / 9.76$

$76.70 / 12.26$

$72.50 / 18.40$

$76.50 / 12.08$

$78.00 / 12.95$

$76.92 / 12.43$

$81.50 / 9.81$

$76.70 / 11.79$
0.14

0.26

0.12

0.70

0.92

0.42

0.93

0.38

\section{Heart rate}

Before tourniquet inflation

5 minutes after

10 minutes after

15 minutes after

20 minutes after

30 minutes after

40 minutes after

After tourniquet deflation

Arterial oxygen saturation

Before tourniquet inflation

5 minutes after

$96.05 / 2.36$

$96.10 / 2.36$

0.95

$97.11 / 3.01$

$97.35 / 2.20$

0.77

$97.79 / 3.22$

15 minutes after

$98.59 / 2.93$

20 minutes after

$98.37 / 2.36$

30 minutes after

$97.93 / 2.61$

40 minutes after

$98.80 / 1.87$

$97.65 / 2.72$

0.88

$97.85 / 2.90$

0.83

$98.16 / 2.75 \quad 0.80$

$98.31 / 2.46 \quad 0.70$

$97.56 / 2.30$ 
The analgesic effect of nitroglycerin added to lidocaine on quality of intravenous regional anesthesia in patients undergoing elective forearm and hand surgery

\begin{tabular}{cccc}
\hline & $\begin{array}{c}\text { LID }+ \text { NTG } \\
\text { group }(\mathrm{n}=20)\end{array}$ & $\begin{array}{c}\text { LID group } \\
(\mathrm{n}=20)\end{array}$ & P value \\
\hline $\begin{array}{c}\text { Visual analogue } \\
\text { scale (VAS) }\end{array}$ & & & \\
$\begin{array}{c}\text { Before tourniquet } \\
\text { inflation }\end{array}$ & $3.56 / 2.57$ & $3.25 / 2.31$ & 0.90 \\
5 minutes after & $1.39 / 0.77$ & $2.25 / 2.12$ & 0.10 \\
10 minutes after & $1.22 / 0.67$ & $1.85 / 2.11$ & 0.26 \\
15 minutes after & $1.06 / 0.23$ & $1.40 / 1.09$ & 0.32 \\
20 minutes after & $1.00 / 0.00$ & $1.16 / 0.50$ & 0.16 \\
30 minutes after & $1.00 / 0.00$ & $1.00 / 0.00$ & 0.99 \\
40 minutes after & $1.00 / 0.00$ & $1.00 / 0.00$ & 0.99 \\
After tourniquet & $1.05 / 0.23$ & $1.15 / 0.93$ & 0.57 \\
deflation & & & \\
\hline
\end{tabular}

The mean onset time of both sensory and motor blockades was shorter in the group received both LID and NTG compared with another group (t test) (Table 3 ).

TABLE 3 - Time of sensory and motor blocks and recovery $\mathrm{n}$ the study subgroups.

\begin{tabular}{cccc}
\hline & $\begin{array}{c}\text { LID + NTG } \\
\text { group (n=20) }\end{array}$ & $\begin{array}{c}\text { LID group } \\
(\mathrm{n}=20)\end{array}$ & P value \\
\hline $\begin{array}{c}\text { Onset time of sensory } \\
\text { blockade (min) }\end{array}$ & $2.94 / 1.02$ & $6.30 / 2.46$ & $<0.001$ \\
$\begin{array}{c}\text { Onset time of motor } \\
\text { blockade (min) }\end{array}$ & $9.69 / 1.02$ & $13.00 / 5.28$ & 0.010 \\
$\begin{array}{c}\text { Recovery time of } \\
\text { sensory blockade } \\
\text { (min) }\end{array}$ & $10.69 / 3.97$ & $7.18 / 2.41$ & 0.002 \\
$\begin{array}{c}\text { Recovery time of } \\
\text { motor blockade (min) }\end{array}$ & $8.40 / 7.17$ & $8.33 / 3.27$ & 0.980 \\
\hline
\end{tabular}

Also, the mean recovery time of sensory blockade was significantly longer in the former group, while the mean recovery time of motor blockade was comparable between them. The frequency of opioid injections were significantly lower in those who administered LID and NTG than another group, but two groups were similar in terms of the mean time of tourniquet deflation, pain severity after tourniquet deflation, onset time of pain appearance, quality of analgesia on both surgeon and patient view, mean time of the first injected dose of opioid, as well as frequency of analgesic injection within first 6 hours after tourniquet deflation (Table 4).

TABLE 4 - Results after tourniquet deflation.

\begin{tabular}{cccc}
\hline & $\begin{array}{c}\text { LID + NTG } \\
\text { group }(\mathrm{n}=20)\end{array}$ & $\begin{array}{c}\text { LID group } \\
(\mathrm{n}=20)\end{array}$ & P value \\
\hline $\begin{array}{c}\text { Time of tourniquet } \\
\text { deflation }\end{array}$ & $33.50 / 7.42$ & $35.71 / 10.59$ & 0.470 \\
$\begin{array}{c}\text { Frequency of opioids } \\
\text { injection }\end{array}$ & $0.11 / 0.31$ & $0.50 / 0.69$ & 0.028 \\
$\begin{array}{c}\text { Pain severity after } \\
\text { tourniquet deflation }\end{array}$ & $2.22 / 0.55$ & $2.54 / 1.71$ & 0.477 \\
$\begin{array}{c}\text { Onset time of pain } \\
\text { appearance }\end{array}$ & $17.17 / 7.48$ & $12.95 / 6.64$ & 0.074 \\
$\begin{array}{c}\text { Quality of analgesia on } \\
\text { surgeon view }\end{array}$ & $0.16 / 0.37$ & $0.40 / 0.50$ & 0.073 \\
$\begin{array}{c}\text { Quality of analgesia on } \\
\text { patient view }\end{array}$ & $0.11 / 0.32$ & $0.35 / 0.49$ & 0.097 \\
$\begin{array}{c}\text { Time of the first } \\
\text { injected dose of opioid }\end{array}$ & $19.17 / 4.53$ & $16.50 / 5.99$ & 0.365 \\
$\begin{array}{c}\text { Frequency of analgesic } \\
\text { injection within first 6 } \\
\text { hours }\end{array}$ & $0.58 / 0.51$ & $0.80 / 0.41$ & 0.142 \\
\hline \begin{tabular}{c} 
hing \\
\hline
\end{tabular} & & & \\
\hline
\end{tabular}

\section{Discussion}

In the present study, we could show the superiority of administrating LID combined with NTG to isolated administration of LID with respect to shortening the onset of sensory and motor block, prolongation of the recovery time of sensory blockade, and decreasing frequencies of opioid injections. However, the two regimens had similar effects on pain severity after tourniquet deflation, onset time of pain appearance, quality of analgesia on both surgeon and patient view, and the time of the injected doses of opioids. In fact, the concurrent use of LID and NTG can result more in high patients' satisfaction and prolonged analgesic effects than the used of isolated LID. Furthermore, no drug-related side effect was pointed in our study subjects. The beneficial effects of the former regimen were achieved using NTG $200 \mu \mathrm{g}$ that might be an optimal drug dosage for this aim. Similar to our study and for the first time, Sen et al. ${ }^{9}$ demonstrated that the NTG with the similar dose of $200 \mu \mathrm{g}$ led to lower that postoperative VAS scores were significantly lower for the first $4 \mathrm{~h}$ postoperatively. In another study by Abbasivash et al..$^{10}$ and using similar dose of NTG as 200 $\mu \mathrm{g}$, the sensory and motor block onset time were shortened, the recovery time of sensory and motor block and onset of tourniquet pain were prolonged, analgesia time after tourniquet deflation was prolonged and tourniquet pain intensity was also lowered in study group with no significant side effects. Besides, Honarmand et al. ${ }^{10}$ revealed that the addition of $400 \mu \mathrm{g}$ NTG to LID improved 
the speed of onset and the quality of anesthesia and decreased tourniquet pain and intraoperative and postoperative analgesic consumption better than the addition of the other two doses of 200 $\mu \mathrm{g}$ or $300 \mu \mathrm{g}$ NTG, without any significant side effects. In fact, although administration of NTG $200 \mu \mathrm{g}$ can be appropriate for obtaining optimal time for the onset of sensory and motor block and recovery time of sensory blockade, but the increase of its dosages up to $400 \mu \mathrm{g}$ can lead to achieving higher quality of anesthesia and more decrease in tourniquet pain ${ }^{11}$. The beneficial effects of NTG seems to be influenced by a direct potent vasodilatory effect that promotes distribution of lidocaine to nerves that is mainly dose dependant and can be increased by elevating drug dosages ${ }^{12-14}$. The details of the pain relieving mechanism of NTG have been well understood. NTG exerts its analgesic effect as it is metabolized to nitric oxide (NO) in the cell ${ }^{15}$. NO causes an increase in the intracellular concentration of cyclic guanosine monophosphate, which produces pain modulation in the central and peripheral nervous systems ${ }^{16}$. NO generators also induce anti-inflammatory effects and analgesia by blocking hyperalgesia and the neurogenic component of inflammatory edema by topical application ${ }^{17}$. The rapid onset of sensory and motor blocks in NTG group than ketamine group could be explained by the direct strong vasodilator effect that promotes distribution of lidocaine to nerves ${ }^{17}$.

In our study, although use of NTG concomitantly with LID resulted in rapid onset of blockade, but its dosage seems not to be suitable for removing tourniquet-related pain or frequency of postoperative requested opioids. Tourniquet pain, which is described as a dull and aching pain sensation, is a well-known limitation of IVRA. Skin compression ${ }^{18}$, tourniquet size ${ }^{19}$, inflation pressure ${ }^{20}$, and adjuvants in the LA solution ${ }^{21}$ have been implicated as factors involved in tourniquet pain. Tourniquet pain is thought to be mediated by impulse propagation via small, unmyelinated, slow-conducting $\mathrm{C}$ fibers ${ }^{21}$. In addition to spinal cord NMDA receptors, NMDA receptors have also been identified on peripheral unmyelinated sensory axons ${ }^{22}$. It seems that higher doses of NTG are needed to neutralize neural impulses and painrelated conducting nerve fibers. It is still need to compare between different adjuvant to discover the ideal one especially for the prolonged post-deflation analgesia. Also, because of considering small sample size, some results related to no differences in the changes of hemodynamic parameters between the intervention and control group might be explained by this subject. Thus, further similar studies with greater sample sizes for obtaining more accurate findings are strongly recommended.

\section{Conclusion}

The adjuvant drug of NTG when added to LID is effective in improving the overall quality of anesthesia, shortening onset time of both sensory and motor blockades, and stabling homodynamic parameters in hand and forearm surgery.

\section{References}

1. Chilvers CR, Kinahan A, Vaghadia H, Merrick PM. Pharmacoeconomics of intravenous regional anaesthesia versus general anaesthesia for outpatient hand surgery. Can J Anaesth. 1997;44:1152-6.

2. Choyce A, Peng P. A systematic review of adjuncts for intravenous regional anesthesia for surgical procedures. Can J Anaesth. 2002;49:32-45.

3. Estèbe JP, Gentili ME, Langlois G, Mouilleron P, Bernard F, Ecoffey C. Lidocaine priming reduces tourniquet pain during intravenous regional anesthesia: a preliminary study. Reg Anesth Pain Med. 2003;28:120-3.

4. Memiş D, Turan A, Karamanlioğlu B, Pamukçu Z, Kurt I. Adding dexmedetomidine to lidocaine for intravenous regional anesthesia. Anesth Analg. 2004;98:835-40.

5. Choyce A, Peng P. A systematic review of adjuncts for intravenous regional anesthesia for surgical procedure. Can $\mathrm{J}$ Anaesth. 2002;49:32-45.

6. Turan A, Karamanloglu B, Memis D, Kaya G, Pamukçu Z. Intravenous regional anesthesia using prilocaine and neostigmine. Anesth Analg. 2002;95:1419-22.

7. Estebe JP, Gentili ME, Langlois G, Mouilleron P, Bernard F, Ecoffey C. Lidocaine priming reduces tourniquet pain during intravenous regional anesthesia: a preliminary study. Reg Anesth Pain Med. $2003 ; 28: 120-3$.

8. Sen S, Ugur B, Aydin ON, Ogurlu M, Gursoy F, Savk O. The analgesic effect of nitroglycerin added to lidocaine on intravenous regional anesthesia. Anesth Analg. 2006;102:916-20.

9. Abbasivash R, Hassani E, Aghdashi MM, Shirvani M. The effect of nitroglycerin as an adjuvant to lidocaine in intravenous regional anesthesia. Middle East J Anesthesiol. 2009;20:265-9.

10. Honarmand A, Safavi M, Fatemy A. The analgesic effect of three different doses of nitroglycerine when added to lidocaine for intravenous regional anesthesia in trauma patients. Ulus Travma Acil Cerrahi Derg. 2011;17:497-503.

11. Lauretti GR, Perez MV, Reis MP, Pereira NL. Double-blind evaluation of transdermal nitroglycerine as adjuvant to oral morphine for cancer pain management. J Clin Anesth. 2002;14:836.

12. Hashimoto S, Kobayashi A. Clinical pharmacokinetics and pharmacodynamics of glyceryl trinitrate and its metabolites. Clin Pharmacokinet. 2003;42:205-21.

13. Furchgott RF, Zawadzki JV. The obligatory role of endothelial cells in the relaxation of arterial smooth muscle by acetylcholine. Nature. 1980;288:373-6.

14. Hashimoto S, Kobayashi A. Clinical pharmacokinetics and pharmacodynamics of glyceryl trinitrate and its metabolites. Clin Pharmacokinet. 2003;42:205-21.

15. Lauretti GR, Perez MV, Reis MP, Pereira NL. Double-blind evaluation of transdermal nitroglycerin as adjuvant to oral morphine for cancer pain management. J Clin Anesth. 2002;14:83-6.

16. Ferreira SH, Lorenzetti BB, Faccioli LH. Blockade of hyperalgesia and neurogenic edema by topical application of nitroglycerin. Eur J Pharmacol. 1992;217:207-9. 
The analgesic effect of nitroglycerin added to lidocaine on quality of intravenous regional anesthesia in patients undergoing elective forearm and hand surgery

17. Tsai YC, Lai YY, Chang CL. Comparison of the effect of EMLA cream, subcutaneous ring anesthesia and a double cuff technique in the prevention of tourniquet pain. Br J Anaesth. 1993;70:394-6.

18. Estebe JP, Le Naoures A, Chemaly L, Ecoffey C. Tourniquet pain in a volunteer study. Anaesthesia. 2000;55:21-6.

19. Tuncali B, Karci A, Bacakoglu AK, Tuncali BE, Ekin A. Controlled hypotension and minimal inflation pressure: a new approach for pneumatic tourniquet application in upper limb surgery. Anesth Analg. 2003;97:1529-32.

20. Gentili M, Bernard JM, Bonnet F. Adding clonidine to lidocaine for intravenous regional anesthesia prevents tourniquet pain. Anesth Analg. 1999;88:1327-30.

21. Gielen MJ, Stienstra R. Tourniquet hypertension and its prevention: a review. Reg Anesth. 1991;16:191-4.

\section{Acknowledgement}

To Hamadan University authorities who offered critical administrative support and managerial services in carrying out the study and also all researchers for their help and support.
Department of Anesthesiology

Hamadan University of Medical Sciences, Hamadan, Iran Telefax: 0098-918-1111606

hkimiaeimd@yahoo.com

Received: August 10, 2012

Review: October 15, 2012

Accepted: November 14, 2012

Conflict of interest: none

Financial source: Hamadan University of Medical Sciences

${ }^{1}$ Research performed to Department of Anesthesiology, Hamadan University of Medical Sciences, Hamadan, Iran.

\section{Correspondence:}

Hosein Kimiaei Asadi 